\title{
La fundación del Studium Generale de Lleida y la tradición jurídica ilerdense
}

\section{The Studium Generale foundation and its juridic tradition}

\author{
JOAN J. BUSQUETA \\ jbusqueta@historia.udl.cat
}

Universitat de Lleida

\begin{abstract}
Resumen: Tras unas consideraciones sobre las relaciones entre el proceso de consolidación de una oligarquía urbana, durante el siglo XIII, y la misma fundación del Estudio General, entre otras razones esgrimidas por la historiografía, reflexionamos, en esta ocasión, sobre la tradición jurídica que ayudaría a definir el contexto normativo fundacional, y, derivado de esto, la necesidad e importancia de aquella primera Facultad de Derecho (Civil y Canónico) surgida en los territorios hispánicos de la Corona de Aragón, así como de los juristas que impartieron sus lecciones y de aquellos que las recibieron.
\end{abstract}

Palabras clave: Universidad de Lleida, fundación, estudios jurídicos medievales

Abstract: After some considerations on the relationships between the process of consolidation of an urban oligarchy, during the 13th century, and the foundation of the General Study, among other reasons given by hisotriography, we reflect, on this occasion, on the legal tradition, that would help define the foundational normative context, and, derived from this, the need and importance of that first Faculty of Law emerged in the Hispanic territories of the Crown of Aragon, as well as of the jurists who taught their lessons and of those who received them.

Keywords: University of Lleida, foundation, judidic medieval studies

\footnotetext{
* Este trabajo se inscribe en el proyecto de investigación HAR 2016_75028_P (2016-2019) del Grupo de Investigación Consolidado en Estudios Medievales de la Universidad de Lleida, «Espai, poder i Cultura».
} 


\section{Consideraciones previas}

Ya hemos tenido ocasión de abordar en otros trabajos nuestra idea de situar la aparición en Lleida del primer Studium Generale erigido en los territorios hispánicos de la Corona de Aragón, su período fundacional, en el marco del proceso de oligarquización que experimenta la ciudad durante el siglo XIII y que tendrá, como colofón, entre otros resultados, la emergencia, a comienzos del siglo XIV, de la institución docente adecuada para su reproducción a través de la formación, especialmente de juristas, pero también de maestros en medicina, artes y, posteriormente, teólogos. ${ }^{1}$ Así, teniendo en cuenta todos los condicionantes, ya destacados por la historiografía, de carácter económico, cultural o de estrategia territorial y política de la monarquía, desde nuestro punto de vista, el privilegio fundacional otorgado por el rey Jaime II, el 1 de septiembre de 1300, previa aprobación del papa Bonifacio VIII, del 1 de abril de 1297, que tras concederle dicha licencia, sugiere que una vez erigido el Studium, los profesores y escolares del mismo deberán gozar de los mismos privilegios, indulgencias, libertades e inmunidades que fueron concedidos por la Santa Sede al Estudio General de Toulouse, ${ }^{2}$ constituye el final de un largo recorrido de crecimiento urbano y maduración institucional del municipio, que corre paralelo a las propias necesidades de la Corona (Busqueta 2012a, 2019). En este sentido, Jaime II remarcaba, en dicho privilegio, como una de las máximas preocupaciones de la monarquía, la instrucción de barones prudentes cuyos conocimientos redundarían en beneficio de sus reinos y tierras, al mismo tiempo que añadía que la mejor manera de hacerlo era evitando que sus súbditos tuvieran que «mendigar en regiones o naciones foráneas la investigación de las ciencias». De ahí la firme voluntad real de establecer, en Lleida, un Estudio General, «tam in iure canonico quam civili, medicina, philosophia et artibus, ac quibuslibet facultatibus aliis et aprobatis scienciis quibuscumque». Y concluía prohibiendo la docencia y el estudio de dichas disciplinas en otro lugar que no fuera la flamante universidad ilerdense. ${ }^{3}$ Como hemos sugerido, este proceso estaba estrechamente vinculado a la consolidación de un grupo de familias dirigentes que fueron capaces, muy pronto, desde comienzos del siglo XIII, de asegurarse la pervivencia en el poder y el

1 En conjunto, se trata de incorporar con mayor fuerza el protagonismo de la institución universitaria en el estudio de la sociedad y las instituciones de la Lleida bajomedieval (Busqueta 2004: 135-178 y 2019).

2 Una buena reflexión sobre el porqué del modelo de Toulouse pretendido por el Papa para el nuevo Estudio ilerdense en Mariano Peset (1998). Aunque el modelo que seguirá la Universidad de Lleida, de acuerdo con la voluntad del rey y de los responsables municipales será el de Bolonia. Los Estatutos fundacionales de 28 de septiembre de 1300 son muy elocuentes en este sentido: «Pese a que ese Estudio goza de todos y de cada uno de los privilegios y libertades que fueron otorgados por la Sede Apostólica al de Tolosa, no queremos imitar totalmente estatutos, constituciones y disposiciones del Estudio de dicha ciudad, ni tampoco someternos a tales, sino que de ellos sólo aceptamos los que uno a uno y deliberadamente hayan sido aprobados por el rey nuestro señor o por la Universidad de nuestro Estudio. Además, podremos renunciar a los que así hayamos adoptado, siempre que nos pareciera conveniente». Traducción del latín al castellano realizada por Antonio Lucena en Joan J. Busqueta, ed. (2000: 21). Un trabajo más reciente en Mariano Peset (2015). El breve del papa Bonifacio VIII permitía la erección de un Estudio General en cualquier lugar de las tierras del rey de Aragón. El documento en Archivo de la Corona de Aragón (ACA), Bulas, legajo 21, núm. 11 (original)

3 Archivo Municipal de Lleida (AML), Fons Municipal, pergamí 68 (original). El texto es bien conocido, citado y transcrito en distintas publicaciones, desde la edición de Jaime Villanueva (1851), así como sus diferentes copias.

SCRIPTA, Revista internacional de literatura i cultura medieval i moderna, núm. 15 / juny 2020 / pp. 148 - 164 ISSN: 2340-4841 · doi:10.7203/SCRIPTA.15.17563 
control de sus resortes municipales. Se trata, como hemos subrayado, de una oligarquía que lidera el progreso de la ciudad y de sus instituciones -municipales y eclesiásticas-, y que completa el círculo consiguiendo el referido privilegio de fundación de la universidad. Y, ciertamente, en una sociedad, como la bajomedieval, donde los estudios universitarios y los grados conceden prestigio a sus detentores, y los equiparan incluso a determinadas categorías sociales, como se ha estudiado bien en el caso de algunas universidades castellanas, ${ }^{4}$ el hecho de dominar o controlar el acceso a dichos estudios y grados constituye un elemento de poder importante, la participación en la formación de las élites urbanas y estatales. Jacques Verger insistía claramente en esta dirección: «Il est également clair qu'à partir du moment, c'est-à-dire, dès l'origine, où les études universitaires ont revendiqué leurs finalités pratiques e leur utilité sociale, les gens de savoir n'ont pu demeurer insensibles aux séductions du pouvoir, ni les hommes de pouvoir indifférents à la collaboration ou à la concurrence qu'ils pouvaient rencontrer chez les clercs et les lettrés issus de l'université» (Verger 1994: 37). Ha sido desde este punto de vista y bajo esta orientación que hemos abordado, en otro lugar, el estudio de algunos de los cargos o funciones de la vida universitaria medieval ilerdense (Busqueta 2012b).

Hechas estas consideraciones previas, centraremos nuestro texto, para esta ocasión, en los siguientes aspectos: una valoración de la tradición jurídica que ayudaría a definir el contexto normativo fundacional, y, derivado de esto, la necesidad e importancia de aquella primera Facultad de Derecho (Civil y Canónico) surgida en los territorios hispánicos de la Corona de Aragón, así como de los juristas que impartieron sus lecciones y de aquellos que las recibieron. Como observó A. García y García, «Las universidades que cultivan ambos derechos se establecen en Italia, Península Ibérica (excepto Palencia, que era teológica, al estilo de París), mediodía de Francia y hasta cierto punto Oxford y Cambridge». Y prosigue destacando la especificidad de la Universidad de Lleida, «única entre las del reino de Aragón peninsular de las que tenemos una información consistente» (2002: 53-54). Una información que reside, sobre todo, en una documentación fundacional muy completa, ya subrayada, entre otros, por Cándido M. Ajo (vol I, 1957-1968), y cuyos análisis más recientes los debemos a Mariano Peset (1988), Francesc Esteve Perendreu (1992) y Juan Pemán (2000, 2002). Veamos.

\section{Tradición jurídica y contexto normativo fundacional}

Efectivamente, el nacimiento del Estudio General de Lleida también se cimienta en una tradición jurídica que remonta, probablemente, en nuestra arriesgada opinión, a la instalación en la ciudad de la orden de canónigos de Sant Ruf de Aviñón, a mediados del siglo XII, en el marco de la conquista feudal de la Lleida islámica. Los «rufinos», destacados protagonistas en el proceso de reforma que vivía la Iglesia en el siglo XII, brillaron, también, por ser grandes expertos en Derecho romano. Tal como analizó Jean Pierre Poly (1978: 200), en Aviñón dispusieron de un prestigioso

4 Entre otras aportaciones: Adeline Rucquoi (1987, 1999), María Isabel Del Val (1989, 1994)

SCRIPTA, Revista internacional de literatura i cultura medieval i moderna, núm. 15 / juny 2020 / pp. 148 - 164 ISSN: 2340-4841 · doi:10.7203/SCRIPTA.15.17563 
Studium donde se enseñaba y difundía el Derecho romano. Muy probablemente, el privilegio de Consulado, y de la figura de los cónsules como máximos responsables del gobierno municipal, ${ }^{5}$ obtenido por la ciudad en 1197, ${ }^{6}$ fundamental en el recorrido de maduración institucional del municipio desde la carta de población de 1150 (Busqueta 2012a), deba mucho, en nuestra opinión, a la proyección de las ideas romanistas, de difusión del Derecho romano que impulsaban los miembros de dicha orden. Y no será por casualidad, sin duda, que durante los primeros años del siglo XIII, al compás del crecimiento económico y social de la ciudad, de una vida urbana muy activa que acumulará un notable volumen de ordenanzas, estatutos, bandos, etc., que será preciso ordenar y poner por escrito para de evitar los frecuentes litigios que originaba, que aparezca en Lleida el primer código de carácter municipal, la primera compilación de derecho urbano propio en Catalunya, las Consuetudines Ilerdenses, ${ }^{7}$ obra del reconocido jurista y cónsul de la ciudad, Guillem Botet, publicadas en 1228. Se trata de un conjunto normativo riquísimo, de una compilación que, más allá de las innovaciones y el carácter pionero en cuanto a la regulación de algunas instituciones, especialmente referentes al derecho de familia, reforzará el protagonismo y el conocimiento de los juristas ilerdenses fuera del ámbito local. Como ha destacado Josep Serrano (2004), las Consuetudines serán la base de muchos otros códigos municipales, incluso del norte del reino de Valencia. Pero aún más, debemos a Antonio Hernández Palmés (1985) un minucioso estudio dedicado a todo el conjunto de derecho civil (general, patrimonial, contractual, familiar y sucesorio) regulado en dichas Costumbres, comparándolo con otros códigos legales como las Costumbres de Tortosa o los Furs de Valencia; un estudio cuya conclusión muestra la posición avanzada en cuanto a la recepción del derecho romano y canónico que suponía la legislación ilerdense. Es más, los mismos Estatuos Fundacionales de la Universidad de Lleida, publicados el 28 de septiembre de 1300, y de los que tendremos ocasión de tratar más adelante, destacan, en relación a las Consuetudines Ilerdenses, que se trata de un conjunto equitativo y favorecedor de la convivencia y el interés de los estudiantes, de manera que el rector podrá admitir dicho texto cuando resuelva casos o conflictos relativos a los estudiantes laicos. ${ }^{8}$

5 Y cabe mencionar que desde fines del siglo XII, ya se ha formado un primer grupo dirigente de la ciudad, integrado por familias procedentes, también, de tierras occitanas y provenzales; entre ellas aparecen los primeros cónsules de 1197, los primeros dirigentes municipales: son los Tolosa, Carcassona, Portareges, Peitaví (Poitiers), Perpinyà, Clavell, Tarascó, Montpeller, etc.

6 En la misma fecha, el rey Pedro el Católico, también otorgó este privilegio a Perpiñán. En cuanto al documento de Lleida: AML, Fons Municipal, pergamino 13. Edición del mismo en Rafael Gras (1988: 188-189). Una escritura que ratifica el protagonismo de los estamentos urbanos en su gobierno cuando declara la absoluta impunidad para aquellas acciones de los ilerdenses que originen daños o injurias a aquellas personas, sean caballeros u otros, que entren en la ciudad después de haber cometido crímenes, heridas, injurias o raptos a habitantes de Lleida.

7 En relación a las ediciones del manuscrito: Pilar Loscertales de Valdeavellano (1946). Y una revisión del texto con traducción al catalán en Joan J. Busqueta (1997).

8 «Consuetudinis civitatis Ilerdae que continent equitatem vel nostrum comodum et utilitatem studentium respicere dignoscuntur, admitere potest rector super causis dirimendis sive negociis studentium laycorum» (Busqueta 2000: 76).

SCRIPTA, Revista internacional de literatura i cultura medieval i moderna, núm. 15 / juny 2020 / pp. 148 - 164 ISSN: 2340-4841 · doi:10.7203/SCRIPTA.15.17563 
Así pues, el hecho de disponer para la Universidad de Lleida de una documentación fundacional tan completa señalada por la historiografía reside también en esta tradición jurídica desarrollada desde la misma conquista de la ciudad, a mediados del siglo XII, que culminará a fines del siglo XIII. Un desarrollo que, efectivamente, correrá paralelo a la consolidación de una élite municipal gobernante al compás del crecimiento económico de la ciudad. Efectivamente, Lleida, en el proceso de maduración de sus instituciones que se produce a lo largo del siglo XIII, irá obteniendo otras concesiones y privilegios de la monarquía, entre los cuales destaca, el de la organización definitiva del régimen municipal, o privilegio de la Paeria (19 de agosto de 1264), donde se hace un reconocimiento explícito de la personalidad jurídica del común, de la «universitas», el conjunto de los vecinos de Lleida; el del tribunal de justicia criminal, conocido como Tribunal de Coltellades (13 de junio de 1300), y, finalmente, y como colofón, el, ya expuesto, de la fundación del Estudio General (1 de septiembre de 1300), acompañando, este último, de una serie de textos que lo completarán y reforzarán. Y como advirtiera Juan Pemán (2000: 27), «los textos fundacionales constituyen un conjunto documental cuya cronología y coherencia interna revelan un cuidadoso trabajo previo de preparación de la nueva Universidad, así como un amplio consenso entre el monarca y las autoridades de la ciudad que se había ido formando durante el largo período de gestación de la misma».

Un proceso que tiene un tiempo inmediato, unos prolegómenos. Citaba el franciscano P. Sanahuja (1947: 170, n.2), para destacar la importancia que tendrían los hermanos menores en el momento de la gestación del Estudio, la carta que dirigió el rey Jaime II, el 8 de abril de 1293, ${ }^{9}$ a los paeres de Lleida ${ }^{10}$ confirmándoles que había recibido, a través de los comisionados franciscanos Fray Pere d'Esplugues, custodio («fratrum minorum custos») y Fray Jordà, guardián («guardianus Ilerde»), su petición para crear un Estudio General en la ciudad, y que en breve respondería. A partir de aquí, y una vez resueltos las tensiones y conflictos que mantenía la Corona con la Santa Sede, derivados de la conquista de Sicilia por Pedro el Grande (Gaya 1949b: 61-63), se produce la mencionada licencia pontificia en 1297, y tres años después, en 1300 y también como hemos avanzado, el documento real de designación de la ciudad de Lleida como sede del Estudio General, con carácter exclusivo para el conjunto de sus tierras. Al día siguiente, el rei promulgaba la Carta ordinationis et inmunitatis Studii Generalis Ilerdensis, donde se ratificaban los estudios de Derecho Canónico y Civil, junto a los de Medicina, Artes y Filosofía, ${ }^{11}$ y se establecían, entre otras disposiciones bien analizadas por Francesc Esteve Perendreu (1992: 57-61), a quien seguimos, relativas al estatuto

9 ACA, RC, reg. 98, f. 21.

10 De acuerdo con Ramon Gaya (1949b: 61), los responsables municipales de aquellas importantes fechas, y, por tanto los protagonistas de la petición, serían: Ramon de Sant Martí, Salvador de Baiona, Pere de Carcassona i Bernat Pallarès, paeres; Ferrer Clavell, Esteve de Cardona, Arnau d'Isona, Jaume Borrell, Jaume de Bas i Pascàs Cairol, consellers.

11 Cabe recordar que los estudios de Teología no se impartirán en el Estudio General hasta avanzado el siglo XV. Estos conocimientos, eso sí, con rango de cátedra universitaria, se obtenían en Lleida en los conventos de franciscanos y dominicos.

SCRIPTA, Revista internacional de literatura i cultura medieval i moderna, núm. 15 / juny 2020 / pp. 148 - 164 ISSN: 2340-4841 · doi:10.7203/SCRIPTA.15.17563 
personal y territorial del Estudio ${ }^{12}$, la elección del rector y consejeros del mismo, justamente, entre los estudiantes foráneos de ambos derechos:

\begin{abstract}
In primis igitur volumus ac ipsi eidem Studio perpetuo indulgemus quod universitas scolarium fforensium qui non sint de civitate Ilerde, clerici vel layci, in utroque iure studentes dumtaxat, habeant potestatem annis singulis sibi eligendi et creandi rectorem, consiliarios ac generalem bedellum et bancarios prout sibi ad utilitatem eiusdem Studii videbitur expediri. Ita quod ipse rector et consiliarii similiter sint forenses. ${ }^{13}$
\end{abstract}

Tres días después, el 5 de septiembre, y junto a un conjunto de cartas anunciando la nueva fundación a oficiales laicos y mandatarios eclesiásticos de los territorios de la Corona, el monarca ratificava aquella exclusividad, con la prohibición de levantar otros centros en otro lugar de la Corona que no fuera la ciudad de Lleida ${ }^{14}$. La normativa fundacional se completaba, durante el mismo mes de septiembre con un documento de compromiso por parte de las autoridades municipales, fechado el día 21, de observar todos los privilegios y estatutos concedidos al nuevo Estudio, de pagar el salario competente a los profesores (en aquel momento: dos doctores en Derecho Civil, dos en Derecho Canónico, un maestro en Medicina; un maestro en Gramática, además del que ya existía beneficiado de la Iglesia catedral, y un maestro de Lógica y Filosofía), reservándose, en principio, la ciudad la elección de los mismos. De pagar, también al estacionario (el responsable de los ejemplares, de los cuadernos de los textos necesarios para los estudios, elaborados a partir de los manuscritos que disponía el Estudio General). De facilitar la vivienda a profesores y escolares, de construir aulas y de delimitar un espacio, un barrio o «burgo universitario», donde regirían los privilegios e inmunidades establecidos. Un texto que sería ratificado el 17 de febrero de 1328 por el rey Alfonso el Benigno ${ }^{15}$.

Finalmente, la publicación de los primeros Estatutos, fechados el 28 de septiembre de $1300^{16}$, tras la elección del primer rector, el arcediano de la catedral de Lleida, Pere de Cabrera, acto celebrado en la iglesia de Sant Martí de la ciudad. Se trata de los estatutos más antiguos conservados en la

12 Una valoración de los privilegios e inmunidades obtenidos en esta Carta, en Salvador Claramunt (1992). Según Claramunt, el documento convertía el Estudio ilerdense en «una especie de tierra de promisión».

13 Roser Gort (2000: 45-51) a partir de AML, Fons Municipal pergamí 69. Jaime Villanueva (1851: 200-297) y Antoni Rubió (2000 reed.: 16-22) transcribieron el documento a partir de ACA, RC, 197, f. 176 yss

14 AML, Fons Municipal, pergamí 70. Ver Roser Gort (2000: 58-59). Ver también Jaime Villanueva (1851: 199) y Antoni Rubió (2000 reed.: 25-26). Estos últimos recogen el texto de ACA, RC, reg. 197, f. 180. Un verdadero monopolio de los estudios superiores que se rompería, sin embargo, durante el reinado de Pedro el Ceremonioso con la fundación de los centros de Perpiñán (1350) y Huesca (1354).

15 Conocemos el texto del 21 de septiembre de 1300 gracias a esta ratificación de 1328; escritura transcrita por Rafael Gras (1988 reed.: 170-174), a partir de AML, Fons Municipal, Pergamí 88 bis (desaparecido), y también por Roser Gort (1997: 79). Ver, por otra parte, Antoni Rubió (2000 reed.: 82-88), a partir de ACA, RC, reg. 474, f. 166v. y ss.

16 Ver edición en Jaime Villanueva (1851: 207-234); Joan J. Busqueta (2000: 71-93)

SCRIPTA, Revista internacional de literatura i cultura medieval i moderna, núm. 15 / juny 2020 / pp. 148 - 164 ISSN: 2340-4841 ·doi:10.7203/SCRIPTA.15.17563 
Península Ibérica y los más completos que conocemos de una universidad en aquellos tiempos (Claramunt 2002: 35), corolario, a nuestro parecer, de la tradición jurídica de la ciudad.

\section{Necesidad e importancia de los juristas}

La sociedad requería juristas ${ }^{17}$ (civilistas y canonistas) para unas ciudades, una Iglesia y un Estado, la Corona de Aragón, que se estaba consolidando en la Península y en el conjunto del Mediterráneo. En este sentido, entre los primeros profesores de Derecho Civil del Estudio ilerdense destaca Pere Despens, figura clave, entre otros encargos de trascendencia política, en todo el desarrollo del proceso que culmina, durante los años 1313-1314, en la incorporación definitiva del Valle de Arán a la Corona, frente a los intereses de la monarquía francesa, del reino de Mallorca y de la corte pontificia. Un proceso que fue muy bien estudiado por Joan Reglà (1951), y en el que Pere Despens, insistimos, tuvo un papel muy relevante en todas las negociaciones sobre el derecho de propiedad del Valle de Arán, ${ }^{18}$ y de ahí la insistencia del monarca ante las autoridades municipales ilerdenses para que no pusieran obstáculos a la salida y ausencia del brillante profesor de Infortiatum. ${ }^{19} \mathrm{La}$ situación generó conflicto y, finalmente, se resolvió, primero con la substitución en la cátedra otorgada, a ruegos del mismo rey, al jurista Guillem Cabot, y con la vuelta posterior a la Universidad de Pere Despens, a partir de mediados de mayo de 1314 (Reglà 1949). La carrera del experto jurista prosiguió como consejero de los reyes Alfonso el Benigno y Pedro el Ceremonioso, de quien llegó a ser vicecanciller, entre los años 1339 y $1340,{ }^{20}$ y, por tanto, de administrar la justicia en los casos de

17 Recogemos las palabras del profesor Antonio García y García (1994: 149): «QQué ofrece a cambio la Universidad a la sociedad? La Universidad forma a la élite preparada para desempeñar los cargos que requieren una preparación académica de la que la sociedad medieval carecía en gran parte hasta el advenimiento de las universidades. Las universidades hispánicas aportan sobre todo juristas y desde el siglo XV también teólogos. Los primeros sirven a la sociedad tanto a nivel secular (civilistas) como eclesiástico (canonistas), mientras que los teólogos se ocupan del estudio del dogma y la moral católica que eren profesados mayoritariamente por aquella sociedad, pero con importantes aportaciones a la sociedad de su tiempo en aspectos como la guerra y la paz, la ética económica, etc. A cambio de estos servicios que los universitarios prestaban a la sociedad, ésta les ofrecía una promoción social, laboral y económica a la que les daba acceso su formación académica».

18 ACA, RC, reg. 336, f. 105. Jaime II ordena a Pere Despens y a Berenguer de Argelaguer que el próximo 1 de mayo de 1314 estén en Les (Valle de Arán) con objeto de iniciar las negociaciones con los comisarios franceses sobre el derecho de propiedad del Valle. Documento transcrito en Joan Reglà (1951, vol. II, doc. 33, p. 314).

19 Los futuros civilistas debían «leen», a lo largo de sus años de estudio, el conjunto de la legislación justinianea: Código, Digesto Viejo, Infortiatum, Digesto Nuevo, Instituciones, Nuevas Constituciones y los Authentica. En cuanto a los canonistas, las obras de estudio eran: el Decreto de Graciano, las Decretales del papa Gregoprio IX, el Liber Sextus del papa Bonifacio VIII, las Decretales Clementinas del papa Clemente V, promulgadas por Juan XXII, las Extravagantes del mismo Juan XXII, la Summa Aurea de Enrique de Segusio (el Hostiense) y los Libros de las Sentencias del maestro Pedro Lombardo.

20 El rey reclama en diversas ocasiones, durante estos años, la presencia del profesor Despens. Ver: ACA, RC, reg. 1055, f. 105v., reg. 602, f. 107, reg. 114, f. 26v. Catalogados en María Teresa Ferrer (coord.) (2011: 189, núm. 630; 192, núm. 640; 195, núm. 655).

SCRIPTA, Revista internacional de literatura i cultura medieval i moderna, núm. 15 / juny 2020 / pp. 148 - 164 ISSN: 2340-4841 · doi:10.7203/SCRIPTA.15.17563 
naturaleza criminal (Sevillano Colom 1950; Trenchs 1979-1980). Pere Despens será, ciertamente, uno de los juristas de confianza del rey Ceremonioso, durante los primeros años de su reinado, hasta el punto que, hacia el final de su carrera, el 15 se septiembre de 1340, obtuvo del monarca privilegio de inmunidad para él y su familia. ${ }^{21}$ Su hijo, Pere Despens, le sucedería como profesor de leyes del Estudio General y asesor, asimismo, de la monarquía, tal como aparece en enero de 1347, cuando el rey, desde Valencia, se dirige a los clavarios del Estudio para que lo dispensen temporalmente de la residencia y de la lectura de Leyes, dado que es requerido en la corte. ${ }^{22} \mathrm{Sin}$ duda Despens, hijo, gozaba ya de gran prestigio: se estaba dirimiendo la sucesión a la Corona, con la intención del rey Pedro, en aquellos momentos, de hacer heredera a su hija Constanza; y para recabar consejo, reunió en Valencia una junta de sabios en ambos derechos y teología (Tasis 1961: 99). Despens era uno de ellos.

El Derecho despertó, desde buen comienzo, gran interés y la monarquía pretendía la participación en Lleida de los juristas más prestigiosos, y, con ello, la mejor formación para futuros funcionarios reales, administradores, consejeros, profesores, etc. Jaime II lo intentará, en septiembre de 1313, y escribirá, «ni más ni menos», como sostuvo A. García y García (2000: 206) que al gran jurista de la corte pontificia de Aviñón, Oldrado da Ponte de Laude, invitándole a venir a impartir las enseñanzas de leyes. ${ }^{23}$ No tuvo éxito esta petición. Oldrado, finalmente, no figurará entre la nómina del personal universitario del Estudio. Pero sí lo harán alumnos que destacarán en el ejercicio de su profesión e ilustres docentes, ${ }^{24}$ como el mallorquín Hug de Fenollet, doctor en leyes, reclamado por el rey para leer en el Estudio General en 1342, y al que aseguraba protección debido al proceso contra Jaime III de Mallorca. ${ }^{25}$ Nombrado canónigo de Lleida y de Girona, vicecanciller del Estudio

21 ACA, RC, reg. 869, f. 217. Catalogado en María Teresa Ferrer (coord.) (2011:196, núm. 659). En una referencia fechada el 16 de octubre de 1344 consta ya como difunto: «Axí meteix que micer Pere Despens que és passat d'esta vida, lo qual ere conseyller dels clavaris...» (AML, Llibre de Consells, reg. 397, f. 50)

22 ACA, RC, reg. 1061, f. 56. Catalogado en María Teresa Ferrer (coord.) (2011: 234, núm. 807).

23 «Jacobus, Dei gratia, rex Aragonum, etc., venerabili et dilecto Oldrado in romana curia advocato, civilis scientie professori. Salutem et dilectionem...». El documento, procedente del Archivo del Escorial, d. III, f. 92v., fue publicado por Ramon Gaya Massot (1949: 42, doc. II).

24 Josep Lladonosa (1970) ofrece un listado de profesores y estudiantes del Estudio General de Lleida a partir de 1430 , entre los cuales un significativo número relacionado con el derecho civil y canónico.

25 ACA, RC, reg. 873, f. 219v. Catalogado en María Teresa Ferrer (coord.) (2011: 209, núm. 708). También, Real Biblioteca el Escorial, Manuscrito d.III, f. 97-98. Reproducimos un fragmento del manuscrito del Escorial: « $\cdot . .$. tenore processus quem fecimus et facimus contra dictum regnum Maioricarum nobis rebellem et subditos suos, possitis venire ad civitatem predictam cum equis, equitaturis, vassella, pecunia, et cum sociis, scutifferis et famulis ad vestrum servicium necesariis et bonis vestris et ipsorum, et ibidem stare, morari ac logere ut prefertur et ab inde recedere salve pariter et secure, cum personis et bonis superius nominatis, vobis tamen et dictis personis iurantibus cum fueritis in dicta civitate in posse curie Ilerde de non procurando aut revelando aliqua que nobis, subditis et terris nostris possent esse nociva vel utilia dicto regni Maioricarum et subditis suis...»

SCRIPTA, Revista internacional de literatura i cultura medieval i moderna, núm. 15 / juny 2020 / pp. 148 - 164 ISSN: 2340-4841 · doi:10.7203/SCRIPTA.15.17563 
General en 1345, ${ }^{26}$ ascenderá a la mitra de Vic (1346-1348), a la de Valencia (1348-1356), donde además ostentará el señorío de Puçol, y desarrollará una labor política muy importante al frente de la Cancillería del rey Pedro, entre 1344 y 1354. Dos años antes, el 27 de agosto de 1342, casaba al rey en Valencia con la que sería su tercera esposa, Leonor de Sicilia (Tasis 1961: 135). O como Berenguer Colom, «doctor eximius decretorum pro tunc ordinarie legentem, in Studio memorato, Decretum hora ordinaria scilicet Tertiarum», a fines del siglo XIV, de quien se conservan dos alegaciones y una repetición, la única que nos ha llegado, hasta el momento de la Universidad de Lleida, sobre la D.1 del Decreto de Graciano. ${ }^{27}$ Bartomeu Maüll, el Maullus, también doctor en decretos, que aparece como «doctor famosus Ilerde cathedraticus», jurista de confianza de la reina Maria. Josep Lladonosa (1970: 103) destaca la pertenencia de Bartomeu Maüll a una familia de potentes mercaderes de la ciudad, cuya residencia estaba en el «carrer de Mahull» (actual calle de Fraga) Antoni Riquer, Gispert Mateu, Simó Sunyer, ${ }^{28}$ doctores en leyes, activos participantes en la gestión municipal, así como política, como síndicos enviados por el municipio a las cortes en numerosas ocasiones, de acuerdo con la investigación realizada por Esther Martí (2006). Pedro de Toledo, de quien se habían conservado, también, algunas cuestiones defendidas y repeticiones, ${ }^{29}$ Manuel de Montsuar,

26 Actúa como vicecanciller, en representación del canciller del Estudio General, Guillem de Bellvís, en el examen y la concesión del título de doctor en medicina a favor de Arnau ça Riera. Textos en ACL, Manual del notario Ferrer Sobrepena, f. 135-138v. Transcriben los textos: Michael McVaugh-Luis García Ballester (1989: 19-25). De hecho, Hug de Fenollet tardó en incorporarse a las lecciones, como denunciaba el clavario Vicent de Montsuar ante el Consejo General de la ciudad, en octubre de 1344 (AML, Llibres del Consell, reg. 397, f. 49-50). Cita Joseph M. Roca (1923: 58-59). Debemos recordar que los clavarios eran los responsables de la contratación y pago de los salarios de los profesores. La Clavería estuvo formada inicialmente por dos representantes del municipio y dos miembros del Cabildo catedralicio, a los que, a partir de fines del siglo XIV, se añadirían dos representantes de la universidad. Sin embargo, para reducir gastos, cada institución sólo conservaría, finalmente, un miembro, de acuerdo con el mandato del papa Benedicto XIII fechado el 25 de octubre de 1413. La Clavería se ocupaba también de la conservación de los edificios del Estudio, de las rentas, de regular las ausencias de los profesores, y de obligar a los docentes a jurar no proceder contra la ciudad ni contra sus privilegios, tal como refiere Josep Lladonosa (1970: 122).

27 El texto se conserva en el Archivo Capitular de La Seu d’Urgell, M. 2.099, f. 95ra-108vb. Cita Antonio García y García (2000: 207; 2002: 70-71). Cabe destacar, también, la petición del rey Juan I, el 24 de octubre de 1391, al rector del Estudio General de Lleida, para que deje acudir a la corte a Berenguer Colom, doctor en decretos, Andreu Terré, doctor en leyes, Arnau Soler, bachiller en decretos y Domènec Mauri, bachiller en leyes, a quienes necesita con urgencia. El documento en ACA, RC, reg. 1879, f. 58; Catalogado en Maria Teresa Ferrer (coord.) (2011: 590, núm. 2433).

28 Esther Martí (2006) ha seguido bien el cursus honorum de estas y otras familias de juristas, como los Agulló, Navarra, Cardona, Desbosch, Riambau, etc., a través de los distintos libros de registros del Archivo Municipal de Lleida. Recogemos un par de ejemplos. En cuanto a Bartomeu Maüll, «Va ser advocat de la ciutat entre 1442 i 1443 , i paer (gobernante municipal) l'any 1451, coetàniament al seu sindicat a les Corts. De fet, entre les dècades de 1440 i 1450 serà consultat per la ciutat en diverses ocasions i participarà en nombroses embaixades» (p. 125). En relación a Simó Sunyer: «Es va llicenciar en lleis, i ja l'any 1408 el trobem formant part del Consell dels Vuit, com a representant de la Mà Major. Va ser paer en diverses ocasions (1418, 1421 i 1435). L'any 1435 ja se’l considerava legum doctori dos anys després exercia d'inquisidor jurista. Se'l devia considerar força, dins i fora de Lleida, ja que a les Corts de 1431 se'l nomenarà proveïdor de greuges pel braç reial, juntament amb Vicenç Padrissa, síndic de Barcelona» (p. 114-115).

29 A. García y García (2000: 207-208) advertía de la dificultad para volver a localizar el Ms.55, donde se hallaba

SCRIPTA, Revista internacional de literatura i cultura medieval i moderna, núm. 15 / juny 2020 / pp. 148 - 164 ISSN: 2340-4841 · doi:10.7203/SCRIPTA.15.17563 
que como miembro del brazo eclesiástico asumirá la presidencia de la Diputación del General en los inicios de la guerra civil de 1462, y llegará a ser canciller del Estudio General (Lladonosa 1950, Busqueta 2011), o Bernabeu Assam, doctor en derecho canónico, paer en 1456, autor de un famoso Tratado de Caballería y miembro, junto al citado Maüll, de la embajada que el gobierno de la Paeria envió, en 1460, ante Juan II para interceder en favor del Príncipe de Viana (Lladonosa, 1970: 96). Y, por poner otro ejemplo, entre tantos, de la importancia del cultivo del derecho en Lleida, especialmente del canónico, debemos destacar el comentario que dedicó al Libro IV de las Decretales del papa Gregorio IX, el obispo Jaume Sitjó (1340-1348), la Cigonina. Una obra que recoge el derecho canónico sobre el matrimonio y que estaba dirigida a los estudiantes de cánones y a los jueces eclesiásticos. En este sentido, y con cierta urgencia, se expresaba la reina Violante, el 25 de mayo de 1387, en una carta dirigida al doctor en derecho canónico, Jordà de Sobrà, ciudadano de Lleida y profesor del Estudio General, que disponía de uno de estos ejemplares:

\begin{abstract}
Entès havem que vos tenits un libre que féu en Cigó, bisbe de Leyda, appellat Cigonina, lo qual libre parla de desfer maleficis. Pregam-vos e manam que de continent, vista la present, lo'ns trametats per lo portador de la present. En en açò dilació o excusa no metats, car Nós lo havem axí de gran necessitat, que no pot ésser maior. Certificant-vos que, de present, lo haiam emprat per çò que mester lo havem, lo us trametrem. Dada en Barchinona, sots nostre segell secret, a XXV dies de maig de l'any MCCCLXXXVII. Dirigtur Jordà de Sobrà, doctor en decrets e ciutadà de Leyda. ${ }^{30}$
\end{abstract}

Sin duda, la nómina de profesores en ambos derechos se enriquece con el paso del estudiante valenciano, procedente de la Torre de Canals en Xàtiva, Alfonso de Borja que llega a los 14 años de edad al Estudio General de Lleida; se doctora, en 1413, a los 35 años, en derecho civil y canónico, ${ }^{31}$

la información sobre los juristas Pedro Díaz de Toledo y Pedro de Toledo, sobrino del anterior, procedente de la Biblioteca de la Universidad Central en Madrid, y que debería estar en los fondos de la Biblioteca de la Universidad Complutense.

30 ACA, RC, reg. 2056, f. 16. Texto de la carta que fue mal interpretado, según B. Marqués $(1978,2003)$ y J. Perarnau $(1987,1996)$. Una mala interpretación que junto al desconocimiento del conjunto de la obra contribuyó a que algunos autores juzgaran la obra del obispo Sitjó de nigromante. Como insiste B. Marqués (2003: 295): «En realitat no és així. Aquesta obra molt extensa sobre el matrimoni, al títol 15 comenta els capítols de la rúbrica del mateix text canònic De frigidis et maleficiatis et impotentia coeundi. I encara més concretament al cap. Litere (c.7), en el comentari al mot Alias, l'autor Jaume Sitjó al ludeix i exposa breument la Practica Constantini de Constant l'Africà, benedictí i metge del segle XI. Aquest passatge de la Cigonina era el que verament interessava a la reina».

31 Alfonso de Borja dirigiéndose, el 6 de julio de 1456, al Capítulo y al conjunto de los ciudadanos ilerdenses: «Nos, igitur, qui in predicta civitate, in Generali Studio, ibidem plurimus annis educati fuimus, ac canonicum et civile iura post doctoratus gradum, que ibidem suscepimus, plublice et ordinarie legimus». El texto transcrito en José Rius Serra (1948: II, 185). De la misma fecha, la bula mediante la cual se declaran exentos de reserva los beneficios de patronato laical para estudiantes del Estudio General, considera, en referencia a su Santidad: «quod dum in minoribus constituta erat, nutrita et educata in civitate Ilerdensi fuerat, in qua per plures annos in Generali Studio Ilerdensi Ius Canonicum et Civile, publice et ordinarie, post doctoratus gradum legerat, ac canonicatum et praebendam in edadem eclesiam obtinuerat». El texto transcrito en Vicente Beltrán de Heredia (1986: 103).

SCRIPTA, Revista internacional de literatura i cultura medieval i moderna, núm. 15 / juny 2020 / pp. 148 - 164 ISSN: 2340-4841 · doi:10.7203/SCRIPTA.15.17563 
llegando a ser uno de los más prestigiosos juristas del momento y consejeros de la monarquía. ${ }^{32}$ Sigue la carrera eclesiástica y asume la cátedra de teología; se convierte en canónigo de la sede Ilerdense, más tarde en vicecanciller del Estudio General, ${ }^{33}$ obispo de Valencia, en 1429, cardenal adscrito a la iglesia de los Cuatro Santos Coronados, en 1444, y, finalmente, sumo pontífice, con el nombre de Calixto III, en 1455. Su sucesor en la curia y famoso humanista Eneas Silvio Piccolomini, papa Pío II, lo calificará de «letrado excelentísimo en la ciencia de las leyes, entre todos los juristas de la época» (M. Domínguez 1985: 13). Desde el pontificado, Calixto III, antiguo beneficiado, también, de la iglesia parroquial de Sant Joan de Lleida, atenderá siempre las peticiones que reciba del municipio, de la Iglesia y, especialmente, del Estudio General, aspecto, este último, estudiado por Francesc Esteve Perendreu (1990). Sin olvidar acciones de gran trascendencia como la revisión del proceso de Juana de Arco, que sería declarada inocente; incoará el proceso de canonización del que fuera su gran mentor durante su juventud, el futuro San Vicente Ferrer, y instituirá para toda la Iglesia la fiesta de la Transfiguración del Señor para conmemorar la recuperación de Belgrado de manos de los turcos (1456), una de sus obsesiones, después de la caída de Constantinopla en $1453 .^{34}$

Y, aunque ya bien entrado el siglo XVI, cabe destacar la gran influencia que ejercería uno de los grandes reformadores del Estudio General de Lleida, el obispo Antonio Agustín, después arzobispo de Tarragona. El obispo Agustín, célebre estudioso del humanismo jurídico, canonista reconocido por sus contemporáneos como «faro del Derecho Canónico», destacó también como historiador del Derecho. ${ }^{35}$

32 Sin olvidar sus orígenes, facilitará, gracias a su acción ante el rey Magnánimo, el acceso de los estudiantes valencianos al rectorado del Estudio General, mediante privilegio concedido por el monarca, de 13 de septiembre de 1419. Una función que, durante más de un siglo había estado vinculada, pese a la normativa al respecto y de manera alternativa, a estudiantes catalanes y aragoneses, tal como recordaba Ramon Gaya (1950: 21). Sin embargo, no será hasta 1427 y con muchas reticencias por parte de las autoridades eclesiásticas y ciudadanas ilerdenses, cuando se produzca el acceso de los primeros rectores valencianos en las personas de Odoardo de Montcada y Nicolau de Montsoriu, tal como se observa en la documentación transcrita por Ramon Gaya (1950: 42-58).

33 No pudo ser canciller en 1420, pese a tener el favor del rey Alfonso el Magnánimo e incluso un primer nombramiento que no se haría efectivo. El gobierno municipal tenía otro candidato, Melcior de Queralt, que fue quien se impuso. En relación a la figura del canciller, cargo que nombraba el rey y era vitalicio entre un canónigo de la sede ilerdense, normalmente el decano del Capítulo, se produjeron diversos enfrentamientos, especialmente durante los reinados de Alfonso el Magnánimo y de Juan II (Busqueta 2012).

34 La bibliografía sobre el primer papa Borja es conocida y muy extensa. Señalamos para el caso de su relación con Lleida, los trabajos clásicos de Juan B. Altisent (1924), de Ramon Gaya (1950), y más recientemente, los recogidos por Ximo Company, ed. (1991).

35 Aunque queda fuera del ámbito cronológico tratado en este trabajo, debo destacar el trabajo reciente de Rafael Ramis Barceló (2018), historiador del derecho y de las universidades, especialmente en época moderna, con un capítulo dedicado a «la Universidad de Lérida durante el pontificado de Antonio Agustín (1561-1576)», pp. 15-54, y una revisión hisoriográfica del período y de la figura objeto de estudio. 
Por otra parte, en aquella primera Universidad se habían formado juristas de la talla de Jaume Marquilles (1368-1451), que se presentaba como «filius Ginmasii Ilerde», vicecanciller de la corte del rey Martín el Humano y, sin duda, el mejor comentarista de los Usatges de Barcelona; Marquilles junto a otros jurisconsultos catalanes del siglo XV, como Jaume Callís, de quien no queda claro su paso por las aulas del Estudio General de Lleida, protagonistas de la elaboración de la teoría pactista del gobierno, del pactismo (Elías de Tejada 1950, Sobrequés 1982).

La importancia que llegaron a tener los estudios jurídicos, así como su necesidad, se observa también en aspectos simbólicos como la posición de privilegio que ocupaban los doctores que impartían aquellas materias en actos oficiales y de ceremonial, respetando, eso sí, la primacía de los profesores de Teología, el saber por excelencia de la Edad Media. Así quedará reflejado en un mandato del rey Pedro el Ceremonioso, de octubre de $1386,{ }^{36}$ cuando, justo antes de comenzar el curso, y siguiendo las normas del Estudio General de Toulouse, establecía el orden jerárquico en el que debían situarse los doctores y maestros del Estudio General de Lleida en los actos oficiales con el objetivo claro de poner fin a las peleas que se producían en este sentido. Así, a las misas, sermones y demás actos solemnes de la vida académica, deberían tomar asiento de la forma siguiente: ocupando la posición central en la mesa, el canciller o el rector; a su derecha y por orden de antigüedad, primero los doctores en Teología y después los doctores en Decretos (Derecho Canónico); a la izquierda, primero los doctores en Leyes (Derecho Civil), después los maestros en Medicina, y a la izquierda de éstos, los maestros en Artes. En cuanto a las salidas por la ciudad, también en actos de solemnidad, tras el rector o el canciller, primero los doctores y maestros en Teología, detrás los doctores en Decretos, los doctores en Leyes, los maestros en Medicina y los maestros en Artes. Por otra parte, a pesar de que desde $1381,{ }^{37}$ los doctores o maestros y licenciados de las distintas disciplinas del Estudio General disponían del derecho a formar colegio, con las mismas prerrogativas que el colegio de doctores y licenciados de Montpellier, con un prior al frente, cargo que ya recaía anualmente y de forma alternativa, precisamente en un doctor de Derecho Canónico y en un doctor de Derecho Civil, ${ }^{38}$ éstos obtuvieron, finalmente, el 15 de mayo de $1410,{ }^{39}$ un privilegio del rey Martín el Humano, firmado en la Torre de Bellesguard, para constituirse en colegio propio y establecer las ordenanzas necesarias para su gobierno. De hecho, todo aquello vinculado al Estudio general, a sus académicos, a su organización, a sus relaciones con el resto de instituciones ciudadanas preocupaba al rey Martín. En ese sentido, en 1399, en un momento

\footnotetext{
36 ACA, RC, reg. 852, f. 185-186

37 ACA, RC, reg. 941, f. 146-147. Documento transcrito por Antoni Rubió (1908, vol. I: 289-290).

38 «In Dei nomine. Pateat universis quod Nos Petrus, etc...Concedimus in speciale privilegium perpetuo, firmiter valiturum, cunctis doctoribus, licenciatis et approbatis in dicto Studio residentibus, presentibus et futuris, quod habeant ammodo et habere possint, collegium, et per se ipsos collegium et corpus facere, et doctorem unum de ipso collegio in priorem eligere singulis annis, scilicet, uno anno canonistam et alio anno legistam...»
}

39 ACA, RC, reg. 2208, f. 87v.-89v.

SCRIPTA, Revista internacional de literatura i cultura medieval i moderna, núm. 15 / juny 2020 / pp. 148 - 164 ISSN: 2340-4841 · doi:10.7203/SCRIPTA.15.17563 
de fuertes tensiones entre la Universidad y los representantes municipales, el monarca ya había determinado una serie de reformas con este objetivo, tal como estudió José Ramón Julià (1992). Uno de los últimos documentos que firmó el rey Martín, sin duda, pues habría de morir muy pronto, el 31 de mayo. Veamos, para terminar, algún fragmento del mismo:

\footnotetext{
Quod Nos Martinus, Dei gratia, rex Aragonum, etc....Tenore presentis, ad humilem supplicacionem doctorum civitatis et Studii Ilerdensis, et perpetuam rei memoriam, vobis universis doctoribus, licenciatis et approbatis, tam in iure canonico quam civili, presentibus et futuris, in dicta civitate residentibus, et in dicto Studio graduatis vel alibi dum et quamdiu residebitis in dicta civitate, concedimus perpetuo per specialmen privilegium, ac cum presenti auctoritatem et plenam facultatem ac liberam licenciam elargimur, habendi, faciendi et representandi verum collegium atque corpus. Quodquidem collegium sive corpus collegium doctorum a modo nuncupetur, necnon ad modum collegii cum sono vel tactu seu pulsacione alicuius campane ut per nuncium per vos ad hoc deputandum, tociens quociens, vobis aut maiori et saniori parti ipsius collegii videbitur collegialiter congregandi, conveniendi et colloquendi in aliqua domo etiam seu loco alio pro parlamento et coloquio inter vos habendo, nostra et cuiuslibet officialis nostri licencia et consensu minimo requisitis...

Item, inde tractatus quoscumque comunes nec non salubria statuta et ordinaciones super prospera fundacione et disposicione felici ac bono statu ipsius collegii, prout vobis seu dicte maiori aut saniori parti videbitur inbiendi, statuendi et ordinandi dum tamen statuenda et ordinanda non ad officium cancellarii dicti Studii nullatenus pertineat seu spectent...

Et prefato collegio, singulis annis unum doctorem de ipsius collegii, gremio et priorem ipsius collegii, scilicet, uno anno canonistam et alio legistam, et si alterius vicibus preficiendi, eligendi, ordinandi et ponendi...

Datum in Turri de Belleguard, Territorii civitatis Barchinone, quintadecima die madii, anno a Nativitate

Domini, millesimo quadringentesimo decimo regnique nostri quintodecimo...
}

\section{Final}

Finalizamos, pues, estas reflexiones sobre la que fue «alma mater» de las universidades fundadas en los territorios hispánicos de la Corona de Aragón. Hemos pretendido ofrecer algunas aportaciones, pero, sobre todo, trasladar la necesidad de dedicar más estudios que contextualicen el nacimiento y evolución del Studium Generale de Lleida en relación, en esta ocasión, con la tradición jurídica de la ciudad y la importancia de los juristas y la Facultad de Derecho. Un prestigio que, por citar un ejemplo final, llevó al doctor en Decretos, Bernat Miquel, canónigo de Barcelona, Vic y Mallorca, y auditor en la curia pontificia de Aviñón, a destacar como mérito, en una petición al rey Pedro el Ceremonioso de recomendación ante el papa Clemente VI, fechada en el mes de enero de 1350, el hecho de haber enseñador Derecho Canónico, durante cuatro años, en el Estudio General de Lleida. ${ }^{40}$ Así pues, juristas y Facultad que contribuyeron, sin duda, a motivar en gran parte la opinión del gran humanista italiano, Lorenzo Valla, quien, a mediados del siglo XV, expresaba, en su Crónica dedicada al rey Fernando I de Antequera, que Lleida era la ciudad más célebre de Catalunya. ${ }^{41}$

40 ACA, Cartas Reales, legajo 87

41 Véase la edición de la Crónica realizada por Santiago Pérez Moreda (2002: 83))

SCRIPTA, Revista internacional de literatura i cultura medieval i moderna, núm. 15 / juny 2020 / pp. 148 - 164 
Joan J. Busqueta. La fundación del Studium Generale de Lleida y la tradición jurídica ilerdense

\section{Bibliografia}

Ajo, C.M. (1957-1968) Historia de las universidades hispánicas: orígenes y desarrollo desde su aparición hasta nuestros días, vol. I0, Ávila, CSIC.

Altisent, J.B. (1924) Alonso de Borja en Lérida (1408-1428) después Papa Calixto III, Lérida, Academia Mariana.

Beltrán de Heredia, V. (1986) Aportació al butllari de l'Estudi General de Lleida (1345-1460), Lleida, Institut d'Estudis Ilerdencs-CECEL.

Busqueta, Joan J. (ed.) (1997) Els Costums de Lleida, Lleida, Ajuntament.

- - (ed.) (2000), Llibre de les Constitucions i Estatuts de l'Estudi General de Lleida. Els Estatuts fundacionals, Lleida,1300, Lleida, Fundació 700 Aniversari.

. (2004) «Lleida, ciutat universitària», dentro de Història de Lleida, vol.III: Baixa Edat Mitjana, Lleida, Pagès Editors, pp. 135-178.

__. (2011) Manuel de Montsuar. Contra l'autoritarisme, Lleida, Alfazeta.

—. (2012a) «Lleida (1150-1300): aproximación al proceso de maduración jurídica e institucional», Revista de la CECEL, 12, pp. 35-49

—_. (2012b) «Oligarquia urbana i ensenyament superior a Lleida: el bidell i el canceller de l'Estudi General», dentro Sabaté, F. (coord..), L’Edat Mitjana. Món real i món imaginari, Catarroja-Barcelona, Editorial Afers, pp.163-169.

—_.(2019) «Sobre l'Estudi General de Lleida a l'Edat Mitjana: algunes qüestions», Millars, XLVI, pp. 145-165.

Claramunt, S. (1992) La primera Universitat de Lleida. Lliçó magistral d'obertura del curs acadèmic 19921993, Lleida, Universitat de Lleida.

. (2002) «Orígenes del mundo universitario: de los Studia a la Universitas», dentro Busqueta, Joan J. / Pemán, J. (coords.), Les universitats de la Corona d'Aragó, ahir i avui. Estudis històrics, Barcelona, Pòrtic, pp. 27-51.

Company, X. (ed.) (1991) Els Montcada i Alfons de Borja a la Seu Vella de Lleida, Lleida, Pagès EditorsAmics de la Seu Vella de Lleida.

Del Val, M.I. (1989) «Universidad y luchas urbanas en la Castilla bajomedieval», Mayurqa, 22 , pp. 213-228.

(1994) «Universidad y oligarquía urbana en la Castilla bajomedieval», dentro Aguadé, S. (coord.), Universidad, cultura y sociedad en la Edad Media, Alcalá de Henares, Universidad de Alcalá de Henares, pp. 131-146.

Domínguez, D. (1985) Els Borja, La Safor, CEIC Alfons el Vell. 
Joan J. Busqueta. La fundación del Studium Generale de Lleida y la tradición jurídica ilerdense

Elías de Tejada, F. (1950) Las doctrinas políticas en la Cataluña medieval, Barcelona, Aymà Editor.

Esteve Perendreu, F. (1990) «Las bulas de Calixto III sobre el Estudio General de Lérida», Analecta Sacra Tarraconensia, 63-64, pp. 257-284.

——. (1992) El régimen jurídico del Estudio General de Lleida (s. XIII-XVIII), Lleida, Pagès Editors.

Ferrer, M.T. (coord.) (2011) Josep Trenchs Òdena. Documents de cancelleria I de mestre racional sobre la cultura catalana medieval, Barcelona, Institut d'Estudis Catalans. [obra que dejó manuscrita Josep Trenchs, a su muerte en 1991].

García y García, A. (1994) «Universidad y sociedad en la Edad media española», dentro Aguadé, S. (coord..), Universidad, cultura y sociedad en la Edad Media, Alcalá de Henares, Universidad de Alcalá de Henares, pp.147-157.

- (2000) «Arengas académicas de la Universidad de Lérida (s. XIV-XV)», dentro Durant, B./ Mayali, L (eds.), Excerptiones iuris: Studies in Honor of André Gouron, Berkeley Univesity, pp. 205-225.

—_. (2002) «La organización de los estudios jurídicos», dentro Busqueta, J.J./ Pemán, J. (coords.), Les Universitats de la Corona d'Aragó, abir i avui. Estudis històrics, Barcelona, Editorial Pòrtic, pp. 53-71.

Gaya Massot, R. (1949) «El Chartularium Universitatis Illerdensis», dentro Miscelánea de trabajos sobre el Estudio General de Lérida, vol. I, Lérida, Instituto de Estudios Ilerdenses-Patronato José Ma Quadrado, pp. 9-47.

_. (1949b) «Comentarios al periodo preparatorio dela fundación del Estudio General de Lérida», Ilerda, XII, pp. 59-72.

- (1950) «Los valencianos en el Estudio General de Lérida», Anales del Centro de Cultura Valenciana, Anejo 3, Valencia, CSIC, pp. 5-58.

Gras, R. (1988, nueva edición) Historia de la Paeria, Lleida, Paeria de Lleida.

Gort, R. (2000) «Documents de l’Estudi General», dentro Busqueta, Joan J./ González, E. (eds.), L'Estudi General de Lleida. Ciutat i universitat en els documents de l'Arxiu Municipal de Lleida, Lleida, Ajuntament de Lleida, pp. 41-242.

—. (2016) L'Estudi General de Lleida al segle XIV, Lleida, Universitat de Lleida

Julià, J.R. (1992) «El Estudio General de Lérida a finales del siglo XIV: las reformas de Martín el Humano», dentro Miscel lània a Josep Lladonosa, Lleida, Institut d'Estudis Ilerdencs, pp. 323-348.

Lladonosa, J. (1950) Manuel de Montsuar (1410-1491), Lleida, Institut d'Estudis Ilerdencs.

—_.(1970) L'Estudi General de Lleida del 1430 al 1524, Barcelona, Institut d'Estudis Catalans.

Loscertales, P. (1946) Costumbres de Lérida, Barcelona, Universidad.

Mc Vaugh, M./ García Ballester, L. (1989) «The Medical Faculty at Early Fourteenth-Century Lérida», dentro A History of Universities, vol. VIII, Oxford, Oxford Univesity Press, pp. 1-25.

SCRIPTA, Revista internacional de literatura i cultura medieval i moderna, núm. 15 / juny 2020 / pp. 148 - 164 ISSN: 2340-4841 · doi:10.7203/SCRIPTA.15.17563 
Joan J. Busqueta. La fundación del Studium Generale de Lleida y la tradición jurídica ilerdense

Marqués, B. (1978) «El Ms. 2874 de l'Arxiu Capitular de La Seu d’Urgell i el seu autor Jaume Sitjó», Urgellia, 1, pp. 367-400.

- (2003) «Cigonina super Quarto Libro Decretalium», dentro Seu Vella. L'Esplendor retrobada, Lleida, Departament de Cultura de la Generalitat-Fundació La Caixa, pp. 294-296.

Martí, E. (2006) Lleida a les Corts. Els sindics municipals a l'època d'Alfons el Magnànim, Lleida, Edicions de la Universitat.

Pemán, J. (2000) «Los Estatutos fundacionales de la antigua Universidad ilerdense (año 1300). Un estudio introductorio», dentro Busqueta, Joan J. (ed.), Llibre de les Constitucions i Estatuts de l'Estudi General de Lleida. Els Estatuts fundacionals, Lleida, 1300, Lleida, Universitat de Lleida, pp. 25-40.

—_. (2002) «El marco jurídico e institucional del Estudi General de Lleida (1300-1717)», dentro Busqueta, J.J. / Pemán, J. (coords.), Les Universitats de la Corona d'A ragó, abir i avui. Estudis històrics, Editorial Pòrtic, pp. 75-115.

Perarnau, J. (1987) «Tres notes entorn de la biblioteca papal (Benet XIII), II, Que és la Cigonina», Arxin de Textos Catalans Antics, 6, pp. 304-306.

—. (1996) «Finalment la Cigonina i la seva nigromància», Arxiu de Textos Catalans Antics, 15, pp. 409-414.

Pérez Moreda, S. (ed.) (2002) Lorenzo Valla, Història de Fernando de Aragón, Madrid, Akal.

Peset, M. (1988) «La fundación y el fuero universitario de Lérida», Hispania, 58 , pp. 515-536.

—. (2015), «Modelos historiográficos de las primeras universidades», Universidades, 65, pp. 9-21.

Poly, Jean P. (1978) «les maitres de Saint Ruf. Pratique et enseignement du droit dans la France méridionale ay XII siècle», Annales de la Faculté de Droit, des Sciences Sociales et Politiques de la Faculté de Sciences économiques de Bordeaux, pp. 183-203.

Ramis, R. (2018) Estudios sobre la Universidad de Lérida (1561-1717), Madrid, Ed. Dykinson

Reglà, J. (1949) «Conflicto en la Universidad de Lérida en 1314 por la substitución de un catedrático», dentro Miscelánea de trabajos sobre el Estudio General de Lérida, vol. I, Lérida, Insituto de Estudios Ilerdenses-Patronato José M. Quadrado, pp. 49-55.

- (1951) La Corona de Aragón y la frontera pirenaica. La lucha por el Valle de Arán (siglos XIII-XIV), 2 vols., Madrid, CSIC

Rius Serra, José (1948) Regesto Ibérico de Calixto III, 2 vols, Barcelona, CSIC-Escuela de Estudios Medievales.

Roca, Joseph M. (1923) L'Estudi General de Lleyda, Barcelona, Ilustració Catalana.

Rubió, A. (2000 reed.) Documents per a l'Història de la cultura catalana mig-eval, 2 vols., Barcelona, Institut d'Estudis Catalans.

Rucquoi, A. (1987) «Sociétés urbaines et universités en Castille au Moyen Âge», dentro Poiron, D. (ed.), Milieux universitaires et mentalité urbaine au Moyen Âge, Paris, Presses de l'Université de ParisSorbonne.

SCRIPTA, Revista internacional de literatura i cultura medieval i moderna, núm. 15 / juny 2020 / pp. 148 - 164 ISSN: 2340-4841 · doi:10.7203/SCRIPTA.15.17563 
Joan J. Busqueta. La fundación del Studium Generale de Lleida y la tradición jurídica ilerdense

Rucquoi, A. (1999) «La cultura y las élites en la Valladolid medieval», dentro Valladolid. Historia de una ciudad, vol. I, Valladolid, Ayuntamiento de Valladolid, pp. 193-215.

Sanahuja, P. (1947) «La Universidad de Lérida y los franciscanos», Archivo Ibero-Americano, VII, p.p. 167-242.

Serrano, J. (2004) «La projecció del Dret de Lleida», Revista del Dret Històric Català, 3, pp. 233-258

Sevillano Colom, F. (1950) «Apuntes para el estudio de la Cancillería de Pedro IV el Ceremonioso», AHDE, XX, pp. 137-341.

Sobrequés, J. (1982) Elpactisme a Catalunya. Una praxi política en la Història del país, Barcelona, Ed. 62.

Tasis, R. (1961) La vida del rei en Pere III, Barcelona, Editorial Aedos.

Trenchs, J. (1979-1980) «Pere Despens, vicecanciller de Pedro el Ceremonioso (1339-1340)», Annals de l'Institut d'Estudis Gironins, XXV-I

Verger, J. (1994) «Université et pouvoir en France», dentro Aguadé, S. (coord.), Universidad, culturay sociedad en la Edad Media, Alcalá de Henares, Universidad de Alcalá de Henares, pp.35-52.

Villanueva, J. (1851) Viage literario a las Iglesias de España, vol. XVI, Madrid. Real Academia de la Historia. 